\section{Fever and leukemoid reaction: A rare paraneoplastic manifestation of bladder carcinoma}

\section{Sir,}

Paraneoplastic syndromes are defined as nonmetastatic systemic effects that accompany malignant disease. These syndromes may occur in up to $10-15 \%$ of malignancies. A few paraneoplastic syndromes have been reported in metastatic transitional cell carcinoma including hypercalcemia, thrombocytosis, eosinophilia, nephrotic syndrome, acanthosis nigricans, dermatomyositis, polymyositis, and leukemoid reaction. ${ }^{[1]}$ Leukemoid reaction has rarely been reported in patients with primary bladder carcinomas. We report a rare case of leukemoid reaction and fever associated with transitional cell carcinoma of the urinary bladder.

A 75-year-old female presented with history of intermittent fever (101-105 $\mathrm{F})$ for three months. She had history of one episode of hematuria six months back. $\mathrm{H}$ er repeated total leukocyte counts varied from 32,800 to $60,000 / \mathrm{mm}^{3}$, with predominance of polymorphs 85 $-90 \%$, and presence of band forms. The patient had Karnofsky performance status scale of 60 . $\mathrm{H}$ er $\mathrm{H}$ b was $9.4 \mathrm{~g} \%$ and platelet count was $3,20000 / \mathrm{mm}^{3}$. She was nondiabetic with normal renal function tests. Blood and U rine $\mathrm{C} / \mathrm{S}$ was sterile. Widal test was negative. X-ray chest was normal. Serum calcium was $8.6 \mathrm{mg} \%$. Serum alkaline phosphatase was raised: $827 \mathrm{IU} / \mathrm{L}$. Peripheral blood smear showed normocytic, normochromic anaemia with adequate platelets. No parasite or abnormal cells were seen. Bone marrow examination showed hypercellular marrow, normoblastic erythropoiesis and marked hyperplasia of leukopoietic series with predominance of myelocytes and meta-myelocytes. The myeloid erythroid ratio was 8:1. M egakaryocytes were adequate with normal morphology. No parasite or abnormal cells were seen. U Itrasound abdomen showed a $48.3 \mathrm{~mm} \times 42.7 \mathrm{~mm}$ echogenic SOL in the right lateral wall of urinary bladder [Figure 1]. Contrast enhanced CT-scan showed large heterogeneous proliferating growth in the antero lateral wall of bladder with full thickness bladder wall involvement. There was no obvious pelvic lymphadenopathy [Figure 2]. Kidneys were normal.
Trans-urethral resection of the bladder tumor was done. Patient had an immediate relief of her fever which never recurred in the postoperative period. Subsequent total leukocyte counts one and two week after surgery were $9,900 / \mathrm{mm}^{3}$ and $9400 / \mathrm{mm}^{3}$ respectively. The histopathology report revealed TCC Grade III infiltrating into deep muscle coat of bladder. Radionuclide bone scan that was done in the view of her raised alkaline phosphatase showed no metastasis. She refused radical surgery and was referred for radical radiotherapy. Patient was advised check cystoscopy three-monthly for first two years, and till her nine months follow-up had no recurrence. $\mathrm{H}$ er hemogram was normal; however the raised alkaline phosphatase had persisted. $\mathrm{H}$ er repeat bone-scan at six months revealed no metastases.

In literature review, we found only six cases of a

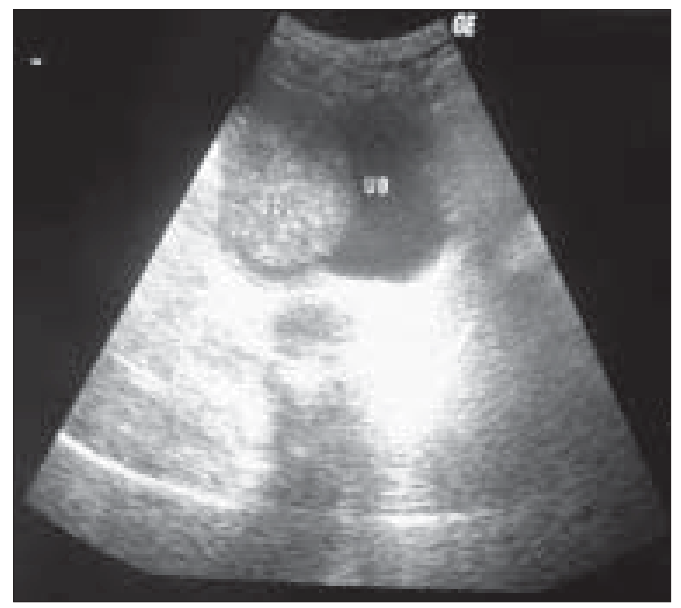

Figure 1: USG showing bladder SOL antero-lateral wall

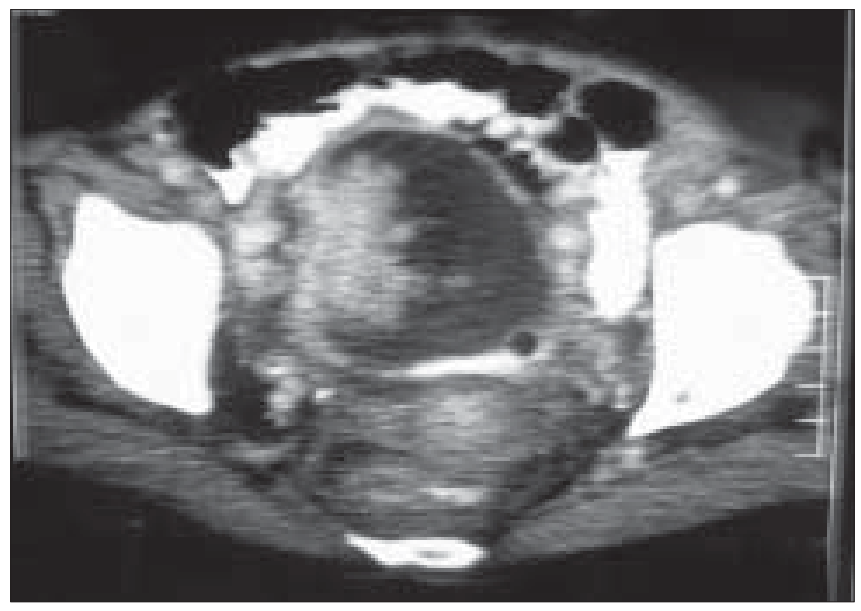

Figure 2: CT scan showing proliferative SOL with full thickness bladder wall invasion 
leukemoid reaction in bladder cancer. All six cases were associated with aggressive tumor cell growth and unfavorable clinical outcome. Only in one of the previously reported cases were fever and leukemoid reaction the presenting features of bladder cancer without any obvious metastases. ${ }^{[2]}$ Two patients had rapid local recurrence six weeks after surgery. ${ }^{[3]} D$ istant liver metastases at initial presentation were present in another two patients. ${ }^{[1,4]}$ In one patient the tumor had already invaded the pelvic wall at the time of diagnosis. ${ }^{[5]}$ L eukemoid reactions probably are caused by mechanical stimuli on bone marrow, resulting from bone metastases, or they may be caused by humoral stimuli resulting from neosynthesized blastic factors or factors released from the foci of tumor necrosis. Paraneoplastic leukocytosis associated with bladder carcinoma has been shown to result from autonomous production of G-CSF by the tumor. ${ }^{[3,4]}$ Fever is an integral component of leukemoid reaction resulting from either release of endogenous pyrogens or due to necrotic-inflammatory phenomena of the tumor.

Fortunately our patient had no recurrence or metastases till nine months follow-up, but these patients should be followed as high risk cases by check cystoscopy and urine cytology-3 monthly for first two years and then annually for lifetime. Chest X-ray six monthly and an annual CT-scan should be done for the first two years for the early detection of the progression of disease.

Mongha R, Narayan S, Das RK, Kundu AK

Department of Urology, Institute of Post- Graduate Medical Education and Research, Kolkata, West-Bengal, India.

Correspondence to: Dr. Ritesh Mongha E-mail: riteshmongha2001@rediffmail.com

\section{References}

1. Bennett JK, Wheatley JK, Walton KN, Watts NB, McNair O, O'Brien DP 3rd. Nonmetastatic bladder cancer associated with hypercalcemia, thrombocytosis and leukemoid reaction. J Urol 1986;135:47-8.

2. Stav K, Leibovici D, Siegel YI, Lindner A. Leukemoid reaction associated with transitional cell carcinoma. Isr Med Assoc J 2002;4:223-4.

3. Tachibana M, Miyakawa A, Tazaki H, Nakamura K, Kubo A, Hata J, et al. Autocrine growth of transitional cell carcinoma of the bladder induced by granulocyte colony stimulating factor. Cancer Res 1995;55:3438-43.

4. Ito N, Matsuda T, Kakehi Y, Takeuchi E, Takahashi T, Yoshida O. Bladder cancer producing granulocyte colony stimulating factor. N Engl J Med 1990;323:1709-10.

5. Ito S, Iwai Y, Fujii T, Yoshida N, Hayashi S. Two cases of bladder tumor producing granulocyte colony stimulating factor. Hinyokika Kiyo 1999;45:57-60. 